\title{
Remote effects in real induction arrows
}

\author{
Antal Ádám \\ Geodetic and Geophysical Research Institute (GGRI), Sopron, Hungary
}

In August 2001, Annali di Geofisica, 44 (4), pp. 659-669, published the paper: «Anomalous directional behaviour of the real parts of the induction arrows in the Eastern Alps: tectonic and palaeogeographic implications» written by Marcus Gurk and Pierre-André Schnegg.

Concerning this paper we have two brief comments.

1) The authors refer to the induction arrows (Wiese vectors) measured in the western part of Hungary as an indication of the eastward continuation of the directional behaviour of the real induction arrows hypothetically connected to the areal distribution of the Mesozoic sediments of the North Penninic Bündnerschiefer-facies. As the Hungarian results were not shown in their paper, for confirmation of the statement of Gurk and Schnegg, a map is given here in fig. 1 on all Hungarian real induction arrows, emphasizing the difference between the generally southward directed induction arrows measured inside the country and those obtained in its western border where the arrows rotate strongly westward according to the anomaly described in the referred paper. The observed tendency is geologically proved by the outcrops of the Penninic rocks in the Köszeg-Rechnitz Mountains. The general

Mailing address: Dr. Antal Ádám, Geodetic and Geophysical Research Institute of the Hungarian Academy of Sciences, Csatkai E. u. 6-8, H-9401 POBox 5, Sopron, Hungary, e-mail: adam@ggki.hu southward direction of the induction arrows in Hungary, i.e. in the Pannonian Basin, is best demonstrated by the arrows measured in Transdanubia (NW Hungary) south of the Lake Balaton where the supposed weak effect of the Carpathian anomaly inside the basin (Ádám et al.,1972) is strongly increased by the pinching out of the Transdanubian Conductivity Anomaly (TCA) (Ádám, 2001) detected between the two great tectonic lines, i.e. the Balaton and Rába line in the area of the Transdanubian Central Range and partly north of it in the Little Hungarian Plain.

2) Arora and Ádám (1992) wrote about an other more general directional characteristics of the real induction arrows experienced in many areas in the world at long periods. We cite from this paper: «...it was found, that straddled between oppositedly directed induction arrows which signify the existence of a conductive structure, a narrow belt exists over which real induction arrows align with the strike of the conductor». A typical example of this phenomenon mentioned by Arora and Ádám is just from the Transdanubian Conductivity Anomaly (TCA) shown in fig. 2 where the direction of the arrows changes from north and south to southwest in two conductive stripes (Wallner, 1977). In Transdanubia, the regional strike is really NE$\mathrm{SW}$ in the conductor as it was determined by different methods including the Groom-Bailey decomposition, the phase maps, the EM distortions, etc. (Ádám, 2001). What is very curious is that inside the conductive stripes, especially 


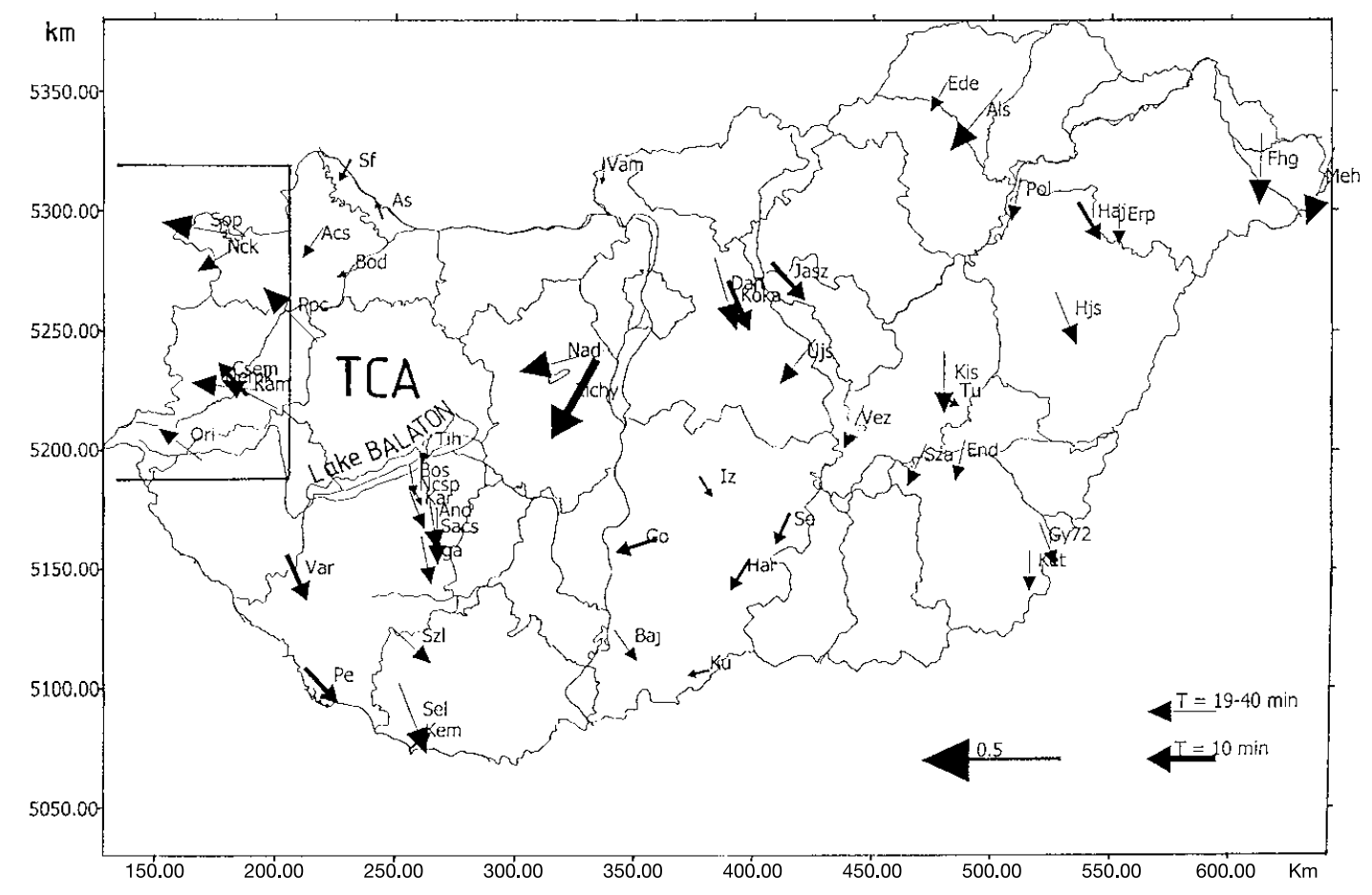

Fig. 1. Real Wiese induction arrows (vectors) measured at a given period in Hungary.

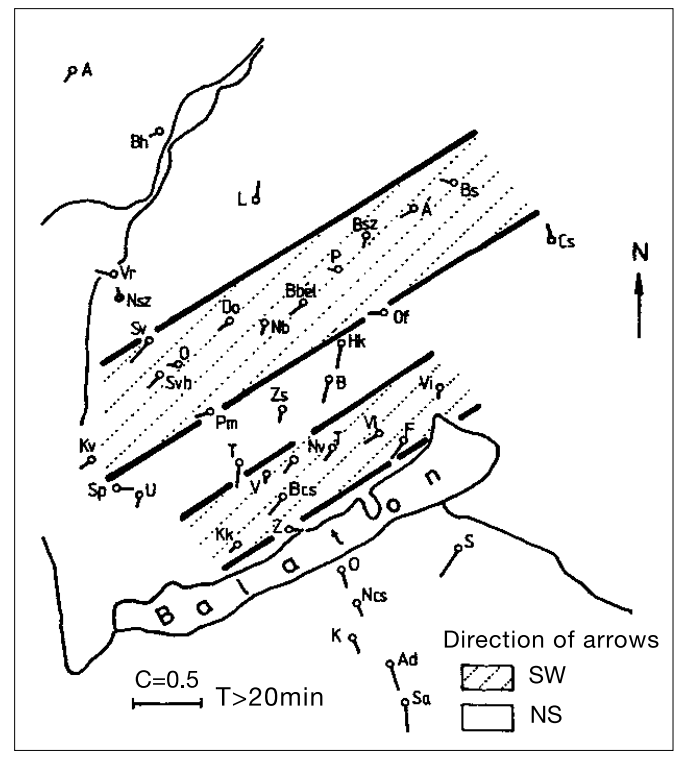

in the southern one, the SW direction of the very small induction arrows is very stable, i.e. it does not change, indicating a remote effect, too. If we look at the block diagram of the geological structures of Western Transdanubia (in fig. 3, Horváth, 1993), we can see that the with P marked Penninic layer underplates, according to the idea of Horváth, not only the Austroalpine nappes (LA,UA) but partly the Transdanubian Central Range where the conductors are certainly embedded in the Paleozoic layers as concluded from the layer sequences and the depth of the conductors $(4-7 \mathrm{~km})$.

Fig. 2. Long period $(T>20 \mathrm{~min})$ Wiese induction arrows in the area of the Transdanubian Conductivity Anomaly measured by GGRI (Wallner, 1977). 


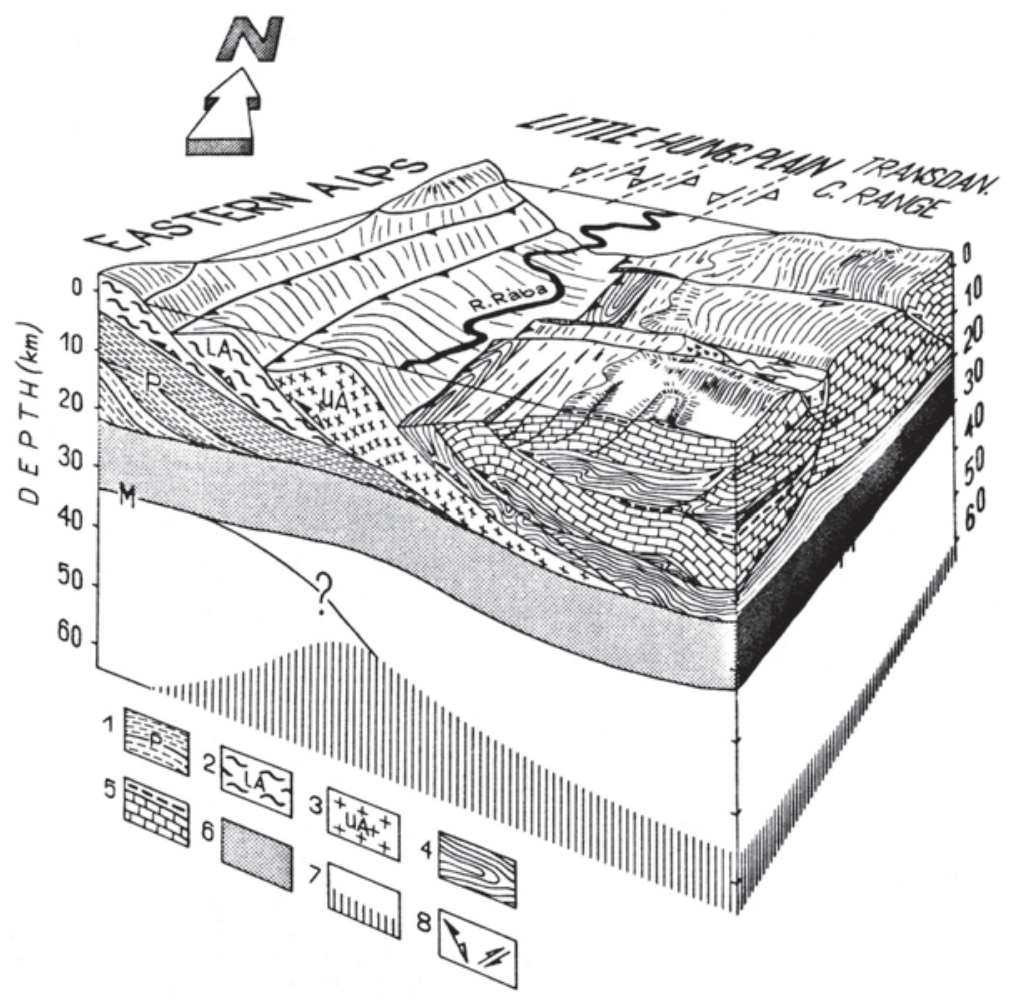

Fig. 3. Block diagram to illustrate the mechanism of lithospheric extension in the Little Hungarian Plain, western part of the Pannonian Basin. Note that there is no vertical exaggeration and block edges are about $100 \mathrm{~km}$ (front) and $80 \mathrm{~km}$ (side) long. Legend: 1 = HP/LT metamorphic rocks of the Penninic (P) nappes; $2=$ medium- to highgrade metamorphic rocks of the lower Austroalpine nappes represented by the Wechsel series in this area; 3 = low- to medium-grade metamorphic rocks of the upperAustroalpine nappes represented by the Graz Paleozoic in this area; $4=$ late Paleozoic low-grade metamorphic rocks of the TCR; $5=$ Jurassic and Triassic of the Transdanubian Central Range (TCR); $6=$ ductile lower crust and the Moho discontinuity; $7=$ lower lithosphere and asthenosphere; $8=$ thrust fault and its reactivation as normal fault and strike slip fault, respectively (Horváth, 1993).

Of course, further geological and geophysical data will help to confirm this supposition.

\section{REFERENCES}

ÁDÁM, A. (2001): Relation of the graphite and fluid bearing conducting dikes to the tectonics and seismicity (Review on the Transdanubian crustal conductivity anomaly), Earth Planets Space, 53, 903-918.

ÁDÁM, A., J. VERO" and Á. WALLNER (1972): Regional properties of geomagnetic induction arrows in Europe, Acta Geod. Geophys. Mont. Hung., 7, 251-287.
ARORA, B.R. and A. ÁDÁM (1992): Anomalous directional behaviour of induction arrows above elongated conductive structures and its possible causes, Phys. Earth Planet. Inter., 74, 183-190.

GURK, M. and P.A. SCHNEGG (2001): Anomalous directional behaviour of the real parts of the induction arrows in the Eastern Alps: tectonic and palaeographic implications, Ann. Geofis. 44 (4), 659-669.

HOVÁRTH, F. (1993): Towards a mechanical model for the formation of the Pannonian basin, Tectonophysics, $\mathbf{6}$, 333-357.

WALLNER, Á. (1977): The main features of the induction arrows on the area of the Transdanubian Conductivity Anomaly, Acta Geod. Geophys. Mont. Hung., 12, 145-150. 
Antal Ádám 